\title{
Metastatic Progression of Prostate Cancer and E-Cadherin
}

\section{Regulation by Zeb1 and Src Family Kinases}

\author{
Aaron P. Putzke, ${ }^{* \dagger}$ Aviva P. Ventura, * \\ Alexander M. Bailey, * Canan Akture,* \\ John Opoku-Ansah, * Müge Çeliktaş, ${ }^{*}$ \\ Michael S. Hwang, ${ }^{*}$ Douglas S. Darling, ${ }^{\ddagger}$ \\ Ilsa M. Coleman, ${ }^{\S}$ Peter S. Nelson, ${ }^{\S}$ \\ Holly M. Nguyen," Eva Corey, " Muneesh Tewari, \\ Colm Morrissey, "Robert L. Vessella," and \\ Beatrice S. Knudsen*\|
}

herin differs in cultured cells versus xenografts, which more faithfully reflect $E$-cadherin regulation in cancers in human beings. Furthermore, the aggressive nature of xenografts positive for E-cadherin and the frequency of metastases positive for $\mathrm{E}$-cadherin suggest that high $\mathrm{E}$ cadherin expression in metastatic prostate cancer is associated with aggressive tumor growth. (Am J Pathol 2011, 179:400-410; DOI: 10.1016/j.ajpath.2011.03.028)

E-cadherin has been used in many studies to observe epithelial-mesenchymal transition (EMT) after stimulation by growth factors. ${ }^{1,2}$ E-cadherin functions as a calciumdependent cell-cell adhesion protein and has a key role in regulating epithelial morphogenesis and differentiation. ${ }^{3}$ Loss of E-cadherin facilitates dissociation of cancer cells from the tumor mass and promotes tumor metastasis. ${ }^{4}$ Several distinct mechanisms have been demonstrated to regulate the level of protein expression. For example, transcriptional repressors bind to E-boxes in the E-cadherin promoter and can cause reversible loss of E-cadherin. These repressors include SNAIL (SNAI1), SLUG (SNAI2), ZEB1 (deltaEF1, TCF8, ZFHX1A, or ZFHEP), ZEB2 (SIP1, SMADIP1, or ZFHX1B), and the basic helixloop-helix transcription factor TWIST, and are believed to participate in global cellular reprogramming during EMT. ${ }^{5}$ The repressors were discovered in model organisms in which activities are temporally coordinated during

Supported by grants W81XWH-08-1-0268 from the Department of Defense; EY017869 and 5 R21 CA118592 from the National Cancer Institute; the Pacific Northwest Prostate Cancer Specialized Programs of Research Excellence (SPORE) NCI 5 P50 CA097186 and PO1 CA 085859-05; and the LUCAS Foundation. CM is a recipient of Career Development Award P50CA097186 from the Pacific Northwest Prostate Cancer SPORE.

Accepted for publication March 8, 2011

Supplemental material for this article can be found on http://ajp. amjpathol.org or at doi: 10.1016/j.ajpath.2011.03.028.

Address reprint requests to Beatrice Knudsen, M.D., Ph.D., Fred Hutchinson Cancer Research Center, Division of Public Health Sciences, Program in Molecular Diagnostics, University of Washington, Seattle, WA 98109. E-mail: bknudsen@fhcrc.org. 
development. ${ }^{6}$ In prostate cancer cell lines, ZEB1 is primarily responsible for transcriptional repression of $\mathrm{E}$-cadherin $^{7,8}$; however, it has not been analyzed in prostate cancer in human beings.

Other mechanisms that regulate $\mathrm{E}$-cadherin are posttranslational. The rate of endocytosis and re-expression after internalization are important factors that affect protein levels and are responsible for rapid loss of E-cadherin expression after growth factor stimulation or oncogenic transformation. ${ }^{9}$ Normally, $\beta$-catenin and $\mathrm{p} 120^{\text {cas }}$ anchor E-cadherin to the actin cytoskeleton via $\alpha$-catenin. This interaction is destroyed by phosphorylation through Src family kinases (SFKs), and E-cadherin is rapidly internalized. ${ }^{10,11}$ After internalization, the MYCN (alias Nmyc) down-regulated gene NDRG1 facilitates surface reexpression from endocytic vesicles, and its levels correlate with those of E-cadherin in prostate cancer tissue samples from patients. ${ }^{12}$

Morphologic changes of EMT that typically accompany the loss of E-cadherin are notably absent even in the most aggressive prostate cancers. Recently, partial EMT in pre-metastatic prostate cancer cells has been proposed. ${ }^{13-15}$ based on reduced expression of E-cadherin and of the tumor suppressor DAB2IP. ${ }^{16}$ Reduced and aberrant expression of E-cadherin is predictive of tumor recurrence ${ }^{17-26}$. However, data from prostate cancer metastases are limited, and the largest study examined only 33 metastatic sites. Three studies of prostate cancer metastases have reported decreased expression compared with the primary cancer, ${ }^{17,27,28}$ and three additional studies have reported high expression $20,29,30$

Based on the complex nature of regulation of E-cadherin expression and the role of E-cadherin in tumor metastasis, the present study measured E-cadherin expression in a large cohort with metastatic prostate cancer and determined the regulation of E-cadherin expression in a novel system of isogenic sublines from metastatic DU145 prostate cancer cells. Together, the data demonstrate E-cadherin regulation through transcriptional and posttranscriptional mechanisms and highlight the difficulties in identifying the causes of E-cadherin loss in prostate cancer.

\section{Materials and Methods}

\section{Cell Lines, Antibodies, and Inhibitors}

DU145, PC-3, C4-2, LAPC4, LNCAP, CWR22Rv1, MDAPCA-2b, and 293T [American Type Culture Collection (ATCC), Manassas, VA] were cultured in ATCC-recommended media. Antibodies to SNAIL, ZEB1, E-cadherin, $\beta$-catenin, $\beta$-actin, $\beta$-tubulin, SrcY419, and SFK were purchased from Cell Signaling Technology, Inc. (Danvers, MA). Anti-CK18 was purchased from Abcam Inc. (Cambridge, MA); anti-E-cadherin (HECD1) from EMD Chemicals, Inc. (Gibbstown, NJ); and Ki-67 from Dako Corp. (Carpinteria, CA). The ZEB1 antibody for $\mathrm{IHC}$ has been validated previously. ${ }^{31}$ Alexa Fluor secondary antibodies were purchased from Invitrogen Corp. (Carlsbad, CA). The TUNEL (terminal deoxynucleotidyl transferase-medi- ated dUTP nick-end labeling) detection kit was purchased from Millipore Corp. (Billerica, MA). Cells were treated with $10 \mu \mathrm{mol} / \mathrm{L}$ PP2 SFK inhibitor (EMD Chemicals, Inc.) and $50 \mu \mathrm{mol} / \mathrm{L}$ E64 (Sigma-Aldrich Corp., St. Louis, MO) or $100 \mathrm{nmol} / \mathrm{L}$ MG132 (EMD Chemicals, Inc.) proteosome/lysosome inhibitors overnight without cytotoxic effect.

\section{Isolation of DU145 Sublines}

DU145 cells from ATCC were sorted using fluorescenceactivated cell sorting (FACS) on the basis of E-cadherin expression and were cultured in three-dimensional Matrigel (BD Biosciences, Franklin Lakes, NJ) at 2000 cells per well. Spheroid structures were extracted and expanded in regular tissue culture, and cell clusters with distinct morphologic features were retrieved via trypsinization. Two sublines, S-DU145 and R-DU145, were obtained from the E-cadherin surface-negative spheres, and one subline, T-DU145, was obtained from the E-cadherin-positive spheres. Cell lines were determined to be stable for more than 50 passages based on morphologic appearance and standard FACS analysis. Isolation of sublines was reproducible with two vials of DU145 cells purchased from ATCC 3 years apart.

\section{FACS and Analysis}

To isolate subpopulations positive or negative for E-cadherin, five million cells were detached from plates using EDTA and were maintained under sterile conditions during staining and sorting. To block the cell surface, cells were suspended in $1 \mathrm{~mL} 5 \%$ bovine serum albumin. After 15 minutes at $4^{\circ} \mathrm{C}, 10 \mu \mathrm{L} \mathrm{HECD1} \mathrm{E-cadherin} \mathrm{antibody}$ was added for 1 hour. After washing, cells were resuspended at approximately one million cells per milliliter and sorted using FACS (Aria 2 cell sorter; BD Biosciences) with a $100-\mu \mathrm{m}$ aperture nozzle. Fractions positive and negative for E-cadherin were counted and plated for culture in growth medium with antibiotics. For FACS analysis, one million cells were labeled in $100 \mu \mathrm{L}$, and were analyzed using the FACS Canto machine (BD Biosciences). Data were analyzed and displayed using the FACSDiva (BD Biosciences, San Jose, CA) and FloJo (Tree Star Inc., Ashland, OR) software.

\section{Matrigel Three-Dimensional Culture}

Cells were cultured in eight-well chamber slides as described, ${ }^{32}$ with the following modification: $80 \mu \mathrm{L} 100 \%$ growth factor-depleted Matrigel was added per well. The chamber slide was placed in the incubator for exactly 1 hour before adding 500 to 1000 cells per well suspended in $400 \mu \mathrm{L}$ ice-cold $10 \%$ Matrigel in phenol red-free RPMI medium. After 48 hours, cells were overlayed with $200 \mu \mathrm{L}$ RPMI $5 \%$ fetal bovine serum and fed every other day for 7 to 10 days.

\section{Migration and Colony Formation on Soft Agar}

Assays were performed as described, ${ }^{33}$ and were repeated twice. 


\section{Human-Specific Quantitative PCR in Xenograft Samples}

RNA measurements of DU145 cells in mouse tibia were performed using the SYBR green method. The human-specific primer sets were as follows: $\mathrm{CDH} 1$ : forward, 5'-CCCCAAAGAAAATACACAATTATCA-3'; reverse, 5'-GTTTCTCAAGTGTTTTGGAGAAAAA-3' SNAI1: forward, 5'-GAAAGGCCTTCAACTGCAAA-3'; reverse, 5'-TGACATCTGAGTGGGTCTGG-3' SNAI2: forward, 5'-GGGGTCTGAAAGCTTGGACT-3'; reverse, 5'-ATGGCCTCTCTCCTCTTTCC-3' ZEB1: forward, 5'-ATGCGGAAGACAGAAAATGG-3'; reverse, 5'-GTCACGTTCTTCCGCTTCTC-3' ZEB2: forward, 5'-GGGTTAGTGCTTTTGTTGTCC-3'; reverse, 5'-CCAAACAGCTTCTCTTCTGAGG-3' RPL13A: forward, 5'-ATTGGAGGGCCCTATCTTGT-3'; reverse, 5'-CCTGTAACCCCTTGGTTGTG-3'

Primer specificity for human sequences was demonstrated with pure mouse bone or bone marrow RNA, and $\mathrm{C}_{\mathrm{T}}>33.5$ cycles were obtained $\left(\mathrm{C}_{\mathrm{T}}=34\right.$ limits of quantification). RNA input for samples from DU145 cells in bone was adjusted to 22 to $23 \mathrm{C}_{\mathrm{T}}$ for human RPL13A and normalized to RPL13A cycle numbers.

\section{Small-Interfering RNA}

ON-TARGETplus SMARTpool small-interfering RNA (siRNA) oligonucleotides (a mixture of four siRNAs) specific to ZEB1, SNAIL, SLUG, ZEB2, and glyceraldehyde3-phosphate dehydrogenase and scrambled pooled siRNA control oligonucleotides were purchased from Thermo Scientific Dharmacon RNAi Technologies (Rockford, IL). Oligonucleotides were transfected using DharmaFECT siRNA transfection reagent (Thermo Scientific Dharmacon RNAi Technologies). In 35-mm dishes, 0.6 to $1 \times 10^{5}$ cells were cultured for 24 hours to $80 \%$ confluence, and were harvested at 48 hours after transfection for RNA isolation and at 72 hours for imaging and protein isolation. siRNA experiments were performed three times, with similar results. Cells lysates were analyzed using Western blot analysis with antibodies to ZEB1 (1:250), SNAIL (1:500), E-cadherin (1:500), $\beta$-catenin (1:500), and $\beta$-tubulin (1:1000). For subcellular fractionation, cells were treated with hypotonic lysis buffer. Nuclei were isolated at $800 \times g$ and, membranes at $1 \times 10^{5} \times \mathrm{g}$

\section{Immunohistochemistry}

\section{TMA of Patients with Cancer}

Tissues were obtained from the Prostate Cancer Donor Program at the University of Washington (Seattle, WA). ${ }^{34}$ A human tissue microarray (TMA) (UWTMA21) was constructed using samples from 44 patients and 185 metastatic sites. Details of metastatic sites are given in Supplemental Table S1 (available at $h$ ttp://ajp.amjpathol.org). $\mathrm{IHC}$ was performed using a standard procedure. In brief, tissues were stained with either E-cadherin (24E10) at a 1:50 dilution, ZEB11642 ${ }^{31}$ at 1:500, ZEB1 (D80D3) at 1:100, or Ki-67 (clone MIB1) at 1:50 after retrieval with Dako Target Retrieval solution (Dako Corp.) for 30 min- utes in a vegetable steamer (Black and Decker Corp., Towson, MD). Tibial xenografts were stained using the ZEB1 (D80D3) antibody. For all other ZEB1 stains, the 1642 antibody was used. Slides were developed using an ABC Kit (Vector Laboratories, Inc., Burlingame, CA) and $3,3^{\prime}$-diaminobenzidine tetrahydrochloride as substrate. TMA cores were scored by two observers (B.S.K., C.A.) on a scale of 0 to 2 in nuclear, cytoplasmic, and membrane compartments. E-cadherin expression was scored in the cytoplasm and membrane, and ZEB1 expression was scored in the nucleus. The staining intensity was multiplied by the percentage of positive cells.

\section{TMA of LuCaP Xenografts}

LuCaP prostate cancer xenografts ${ }^{35}$ were derived as follows: LuCaP 23.1, 35, 58, 78, 81, 92, 115, and 145.2 xenografts were derived from lymph node metastases; LuCaP 23.12, 70, 145.1, and 147 xenografts from liver metastases; LuCaP 49 from omental fat; LuCaP 73 from primary prostate cancer; LuCaP 77 and 105 from bone metastases; LuCaP 86.2 from bladder metastasis; LuCaP 93, 96 and 141 from transurethral resection of the prostate; and LuCaP 136 from ascites. The staining intensities of E-cadherin and ZEB1 were scored by two observers (A.V. and B.S.K) on a scale of 0 to 3 . All cells in the xenografts stained uniformly. The mean score of duplicate cores was calculated.

\section{Tibial Prostate Cancer Model}

Animal studies were performed in compliance with the University of Washington Institutional Animal Care and Use Committee and the National Institutes of Health guidelines. ${ }^{36}$ Mice were sacrificed at 7 to 10 weeks after injection. In two animals per group, tibiae were fixed in 10\% formalin, demineralized in $5 \mathrm{mmol} / \mathrm{L}$ EDTA, and embedded in paraffin. In three animals, tumor cells were flushed from the tibiae and cultured. Cancer cells that remained in the bone after flushing were snap-frozen for RNA isolation.

\section{Statistical Analysis}

Statistical analysis of human metastasis TMA data were performed using $R$ software (version 2.11.1). Because the consistency of scores between duplicate cores was $73 \%$, averaged intensities were used for analysis. Correlations between overall, membrane, and cytoplasm intensity were tested using Pearson's $\chi^{2}$ test in pairs because intensity associations within a patient were higher than between patients. One-way analysis of variance was used to examine differences between bone, liver, and lymph nodes. Equal variance assumption was evaluated using the $F$ test. $P<0.05$ was considered statistically significant. Statistical analysis of laboratory data was performed using functions provided by Excel (Microsoft Corp., Redmond, WA), including Student's $t$-test and the Pearson correlation coefficient. 


\section{Results}

\section{E-Cadherin Expression in Prostate Cancer Metastases}

To determine the frequency of E-cadherin expression in metastatic prostate cancer, a large cohort of prostate cancer metastases was analyzed. The HECD1 antibody, which binds to an extracellular epitope of E-cadherin, was used to measure E-cadherin expression in a cohort of 185 prostate cancer metastases from 44 patients (Table S1). Data were obtained from 165 metastatic sites, of which 109 were bone and 56 were soft tissue. In metastatic tissues, E-cadherin expression ranged from virtually no staining to intense staining (Figure 1A; see also Supplemental Figure S1 at http://ajp.amjpathol.org). There was a strong correlation between membrane and cytoplasmic E-cadherin immunoreactivity $(P<0.01)$. In addition to variable expression across patients, there was considerable variability across metastatic sites from the same patient, as demonstrated by the standard deviations in Figure 1A. Overall, E-cadherin protein expression was significantly higher in bone versus soft tissue metastases $(P<0.01)$ (Figure 1B). The soft tissue metastases were observed in 30 lymph nodes, 18 livers, and 8 other sites. Within patients, $68 \%$ of lymph node and $65 \%$ of liver and other soft tissue metastases expressed lower levels of E-cadherin when compared with the corresponding bone metastases (Figure 1C).

Inasmuch as transcriptional and posttranslational mechanisms of E-cadherin regulation have been identified, ${ }^{37}$ it was questioned whether E-cadherin protein expression was subject to posttranscriptional regulation in a panel of 21 LuCaP prostate cancer xenografts from various metastatic sites (see Materials and Methods). ${ }^{36}$ The relative mRNA expression of E-cadherin was extracted from an array data set, ${ }^{38}$ and the protein was measured using $\mathrm{IHC}$ (Figure 1D). The correlation between E-cadherin RNA and protein expression was $\sigma=0.4$. As observed in the LuCaP78 xenograft, even low expression of E-cadherin mRNA is sufficient to yield high protein expression. Thus, low E-cadherin protein expression in LuCaP 93, 81, 145.2, 58, and 147 is likely due to posttranscriptional regulation.

\section{Characterization of Isogenic DU145 Sublines}

It was postulated that prostate cancer cell lines derived from metastatic cancers might reflect the heterogeneity of E-cadherin expression in metastatic tissues. To test this hypothesis, expression of E-cadherin was analyzed using FACS in VCaP, LaPC4, LNCaP, MDA-PCA-2b, CWR22Rv1, DU145, and PC3 cell lines (data not shown). Except for PC3 and DU145 cells, the cell lines consisted predominantly of cells positive for E-cadherin. While PC3 cells (newly purchased from ATCC) contained two distinct E-cadherin-positive and E-cadherin-negative populations, E-cadherin expression in DU145 cells ranged across a continuous spectrum of cell surface expression (see Supplemental Figure S2A at http://ajp.amjpathol.org). Next, RNA expression of E-cadherin and of the E-cadherin repressors SNAIL, SLUG, ZEB1, and ZEB2 were determined. All cell lines
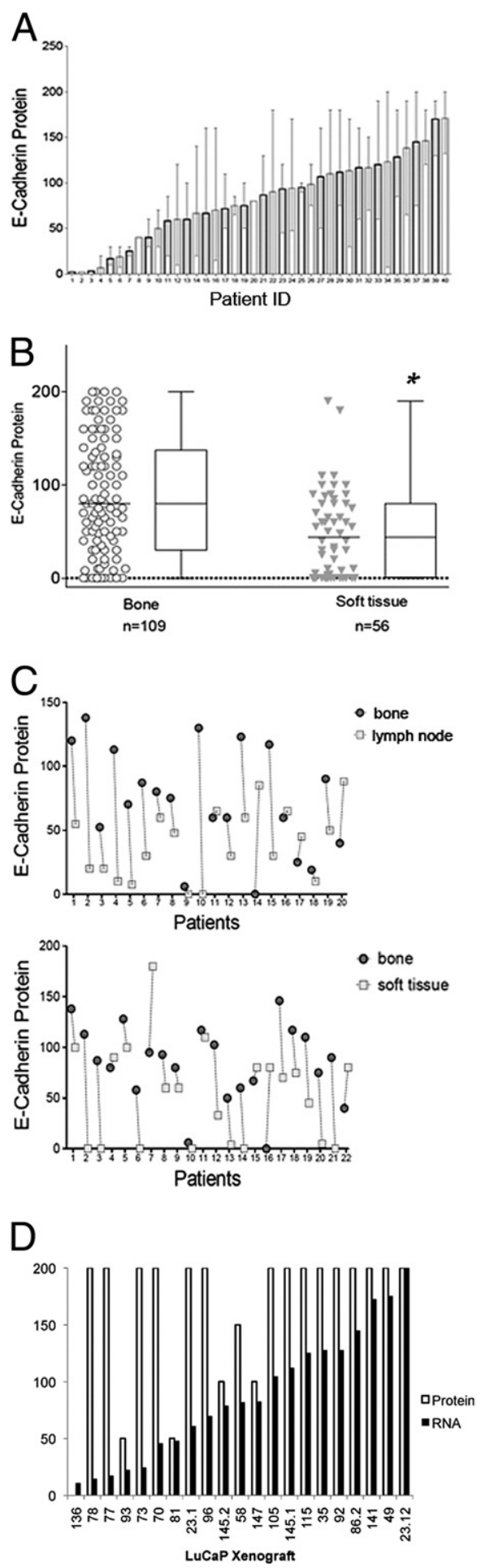

Figure 1. E-cadherin expression in metastatic prostate cancers. A: E-cadherin protein in 40 patients. Bars represent average expression from all metastatic sites in a patient, and SD demonstrates the variability of expression. B: E-cadherin expression in bone versus soft tissue metastases. Circles represent mean intensity scores from duplicate cores. Bone metastases are from 40 patients, and soft tissue metastases from 23 patients. The difference between bone and soft tissue metastases is statistically significant $\left({ }^{*} P<0.01\right)$. C: Contrast of E-cadherin expression between metastatic sites in the same patient. Solid circles represent bone metastases, and open circles represent lymph node metastases (top panel) or soft tissue metastases (bottom panel). Lines connect metastases in the same patient. D: E-cadherin RNA and protein expression in prostate cancer xenografts. RNA data are from oligonucleotide arrays (Agilent Technologies, Inc., Santa Clara, CA), and protein expression data are from a xenograft TMA. 


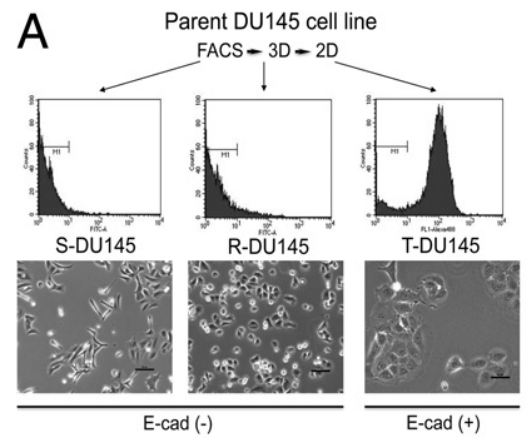

B
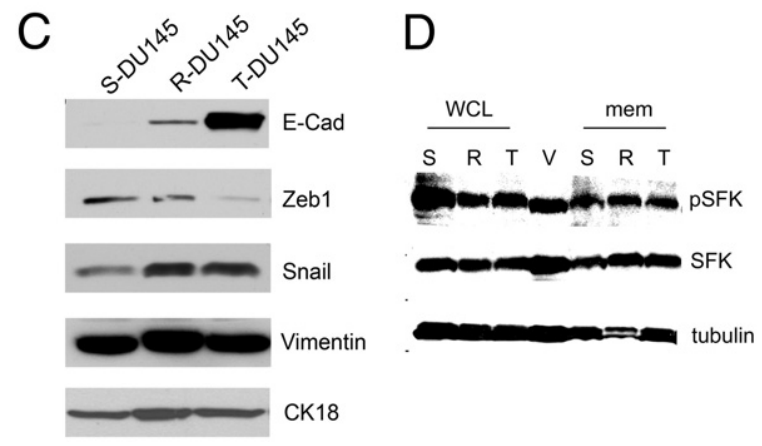
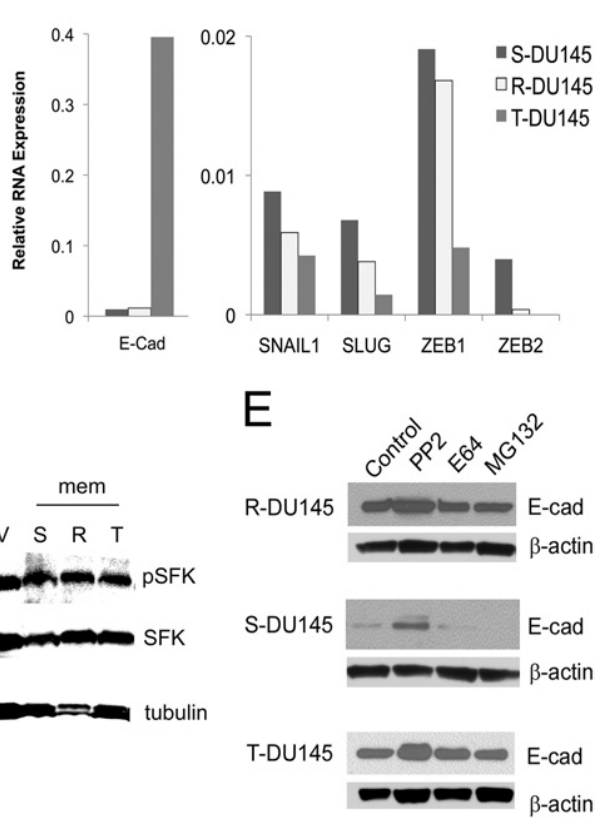

Figure 2. Isolation of isogenic sublines from DU145 prostate cancer cells based on expression levels of E-cadherin (E-cad). A: Generation of spindle (SDU145), round (R-DU145), and tight (T-DU145) sublines. Parent DU145 cells were sorted using FACS based on E-cadherin expression. Cells with the lowest $10 \%$ and highest $10 \%$ E-cadherin expression were placed in three-dimensional Matrigel, and resulting spheres were picked individually and propagated in two dimensions. Scale bars $=50 \mu \mathrm{m}$. B: RNA expression of E-cadherin and E-cadherin repressors SNAIL1, SLUG, ZEB1, and ZEB2. Quantitative PCR cycle numbers were normalized to RPL13A. C: Protein expression of E-cadherin and E-cadherin repressors. Fifty micrograms of whole-cell lysates was analyzed for E-cadherin, vimentin, and cytokeratin 18 (CK18), and $25 \mu \mathrm{g}$ nuclear protein was analyzed for ZEB1 and SNAIL. D: Expression of SFKs in DU145 sublines. Fifty micrograms of membrane (mem) fraction or wholecell lysates (WCL) from S-DU145 (S), R-DU145 (R), and T-DU145 (T) was analyzed for expression of pSFK. The blot was reprobed to determine SFK and $\beta$-tubulin expression. WCL from VCAP (V) cells were used as a positive control. E: Regulation of E-cadherin expression by SFK. R-DU145, S-DU145, and T-DU145 were treated with the SFK inhibitor PP2 or with the proteosome inhibitors E64 or MG132. WCL were analyzed for E-cadherin protein expression. expressed E-cadherin RNA and cell surface protein; however, only DU145 and PC3 expressed high levels SNAIL, SLUG, and ZEB1 (see Supplemental Figure S2B at $h t t p: / /$ ajp.amjpathol.org).

\section{Generation of Isogenic Sublines from the DU145 Prostate Cancer Cell Line}

Because DU145 cells express a range of E-cadherin, this cell line was selected for further analysis. However, E-cadherin-positive and E-cadherin-negative cells could not be stably propagated in two-dimensional culture; therefore, an attempt was made to stabilize cells using three-dimensional culture in Matrigel. DU145 cells were separated into two populations: an E-cadherin-positive population and a population that did not express E-cadherin on the cell surface (Figure 2A). Some surface-negative cells express E-cadherin in the cytoplasm. Cells were cultured in Matrigel, and spheroid structures were picked at 10 days after plating. Further expansion of the cells occurred in twodimensional culture. After this procedure, the cells were stable insofar as structure and E-cadherin expression for more than 50 passages. Three distinct morphologic features were identified. The E-cadherin surface-negative population gave rise to the fibroblastic and elongated (spindle) subline S-DU145 and to the small, epithelioid, and refractile (round) subline R-DU145. The E-cadherin-positive population gave rise to the tight subline T-DU145, which consisted of large cells in cohesive colonies with smooth borders (Figure 2A). Growth rates of S-DU145, R-DU145, and T-DU145 sublines in culture were similar (data not shown), as was expression of cytokeratin 18 and vimentin (Figure 2C).

Parallel to the expression of surface E-cadherin protein, E-cadherin RNA expression was higher in T-DU145 cells than in S-DU145 or R-DU145 cells (Figure 2B). To confirm that RNA expression is regulated transcriptionally and not by RNA stability, a luciferase reporter was used, driven by the proximal $1 \mathrm{~Kb}$ of the $\mathrm{E}$-cadherin promoter (see Supplemental Figure S2C at http://ajp.amjpathol. org). Luciferase activity paralleled cellular E-cadherin expression (Figure 2B). Next was determined which repressor is involved in E-cadherin silencing in DU145 cells. ZEB1 but not ZEB2 or SNAIL RNA expression was inversely related to E-cadherin expression in DU145 and PC3 cells (see Supplemental Figure S2D at http://ajp. amjpathol.org), corroborating findings of a previous study of PC3 cells. ${ }^{7}$ Western blot analysis demonstrated a small amount of E-cadherin in R-DU145 cells (Figure 2C), and ZEB1 and SNAIL protein levels in nuclei isolated from the sublines paralleled their RNA expression levels. The E-cadherin protein in R-DU145 cells is cytoplasmic, as visualized using immunofluorescence (data not shown).

Although E-cadherin RNA was low in S-DU145, it was clearly present, pointing to additional translational or posttranslational inhibition of expression. The responsible known mechanisms are phosphorylation by SFKs and proteosomal degradation. ${ }^{39}$ In all three sublines, phospho-SFKs were detectable, and S-DU145 cells expressed the most SFK (Figure 2D). Treatment with PP2 but not E64 or MG132 increased expression of E-cadherin protein in all sublines, confirming the role of SFKs as regulators of E-cadherin expression (Figure 2E). 

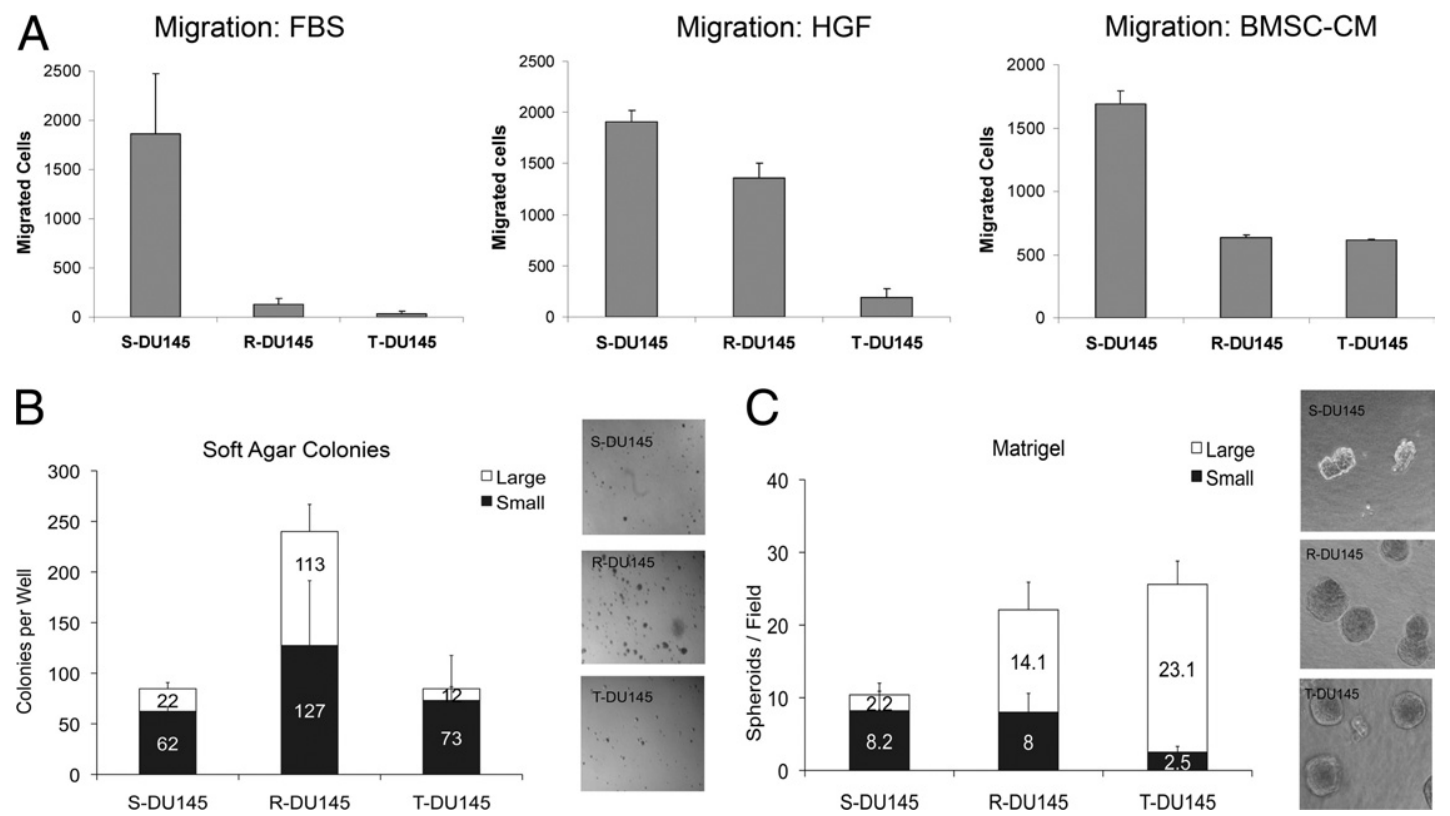

Figure 3. Functional characterization of DU145 sublines. A: Migration of cells through Transwell filters. To the upper chamber, $1 \times 10^{5}$ cells in RPMI were added, and the lower chamber contained either $1 \%$ fetal bovine serum (FBS), $1000 \mathrm{U} / \mathrm{mL}$ hepatocyte growth factor (HGF), or serum-free conditioned medium from bone marrow stroma cells (BMSC-CM). For HGF migration, filters were coated with Matrigel, and cells were allowed to migrate for 6 hours, then were fixed, stained, and counted. Six fields were counted per filter and averaged, and the background spontaneous migration (no attractant) was subtracted. B: Soft agar colony formation assay. Left panel, Cells, $1 \times 10^{6}$, were encased in top agar and grown for 2 weeks. Right panel, Plates were photographed at $4 \times$ magnification, and colonies were counted, with the large and small colonies differentiated at $0.5 \mathrm{~cm}$ in diameter. C: Matrigel assay. Left panel, Cells, $1 \times 10^{3}$ per well of a four-well chamber slide, were grown for 10 days in Matrigel. Right panel, Wells were photographed at $10 \times$ magnification for counting.

\section{Functional Characterization of DU145 Sublines}

The sublines were characterized in several functional assays. As expected, S-DU145 cells were most migratory (Figure 3A). R-DU145 migrated substantially more in response to hepatocyte growth factor/Matrigel than to fetal bovine serum or serum-free conditioned medium from bone marrow stroma cells. T-DU145 cells were the least migratory. In the soft agar colony formation assay, R-DU145 formed the largest number of colonies and the highest percentage of large colonies (Figure 3B). In contrast, in the Matrigel spheroid-forming assay, T-DU145 formed the largest spheroids, with a smooth edge but without a lumen (Figure 3C), which suggests that E-cadherin expression facilitates organized spheroid growth. In both three-dimensional systems, spheroid formation by S-DU145 cells was the slowest, and the spheres were poorly organized. In summary, the three sublines differ significantly in multiple functional assays. While mesenchymal S-DU145 cells are associated with rapid cell migration, the enhanced ability of R-DU145 cells to form colonies on soft agar suggests that these cells are the most transformed.

\section{Regulation of E-Cadherin Expression in Cultured Prostate Cancer Cell Lines}

Because E-cadherin and ZEB1 expression levels are inversely related, it was determined whether ZEB1 is responsible for suppressing E-cadherin in knockdown experiments. In a comparison of cells transfected with siZEB1, siSNAIL, siSLUG, and siZEB2, R-DU145 demonstrated a larger increase in E-cadherin RNA expression than did S-DU145 after siZEB1 but not the other siRNAs (see Supplemental Figure S3, A and B, at http://ajp. amjpathol.org). R-DU145 was used for confirmatory protein measurements, and S-DU145 for morphologic analysis because reversion to an epithelial structure is best observed in these cells. Using Western blot analysis, both E-cadherin and $\beta$-catenin protein expression increased on reduction of ZEB1 but not of SNAIL (Figure 4A). In addition, on reduction of ZEB1, the mesenchymal S-DU145 cells assumed an epithelial structure (Figure 4B).

\section{Cell Line Xenograft Model with R-DU145}

To evaluate the behavior of DU145 sublines in bone, cells were injected into mouse tibia. Whereas S-DU145 cells could not grow, R-DU145 and T-DU145 reproducibly formed tumors with osteolytic activity (Figure 5A). T-DU145 cells generated the largest osteolytic lesions, significantly greater than R-DU145 cells $(P<0.05)$ (Figure $5 B$ ). The rates of proliferation of cells in T-DU145 and R-DU145 xenografts were similar; however, rates of apoptosis differed significantly $(P<0.05)$ (Figure 5, C and $D$ ). When the sublines were grown as subcutaneous tumors to obtain more accurate growth measurements, R-DU145 xenografts varied in onset and growth rates, which suggests that R-DU145 cells are more heterogeneous (see Supplemental Figure S4 at http://ajp.amjpathol. org).

Tibial tumors showed a marked increase in E-cadherin RNA compared with preinjection R-DU145 cells, whereas ZEB1 and SNAIL RNA expression remained the same (Figure 6A). For protein measurements comparing prein- 

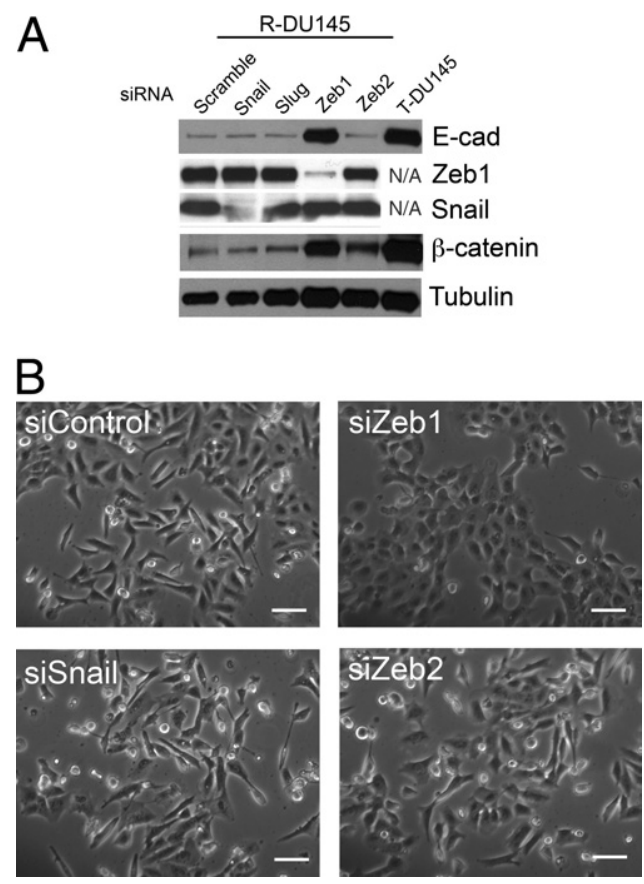

Figure 4. Transcriptional regulation of E-cadherin in DU145 sublines. A: Knockdown of E-cadherin repressors. SNAIL, SLUG, ZEB1, or ZEB2 expression was reduced in R-DU145 cells using a SMARTpool of 4 siRNAs for each gene. Twenty-five micrograms of protein was probed for expression of E-cadherin (E-cad), ZEB1, SNAIL, or $\beta$-catenin. T-DU145 served as a positive control in lanes 1, 4, and 5. B: Morphologic analysis after transfection with siRNAs. S-DU145 cells were transfected and photographed after 72 hours. The transfection efficiency, evaluated with GFP, was $>80 \%$ (data not shown). Scale bars $=100 \mu \mathrm{m}$.

jection R-DU145 cells with those in tibial tumors, R-DU145 cells were retrieved from the tibial shafts and expanded in culture. Greater than $50 \%$ of the cells maintained E-cadherin expression in culture (data not shown). Using Western blot analysis, total E-cadherin and $\beta$-catenin levels were elevated in tibial R-DU145 cells compared with preinjection cells (Figure 6B). In contrast, expression of ZEB1 or SNAIL proteins varied among the cells retrieved from xenografts; however, there was no consistent decrease to explain increased E-cadherin levels. Further, ZEB1 protein expression at $\mathrm{IHC}$ revealed similar nuclear staining intensities in E-cadherin-positive and E-cadherin-negative areas of the xenograft (Figure $6 C)$. To determine the relationship between ZEB1 and E-cadherin protein expression in metastatic prostate cancers in patients, expression of ZEB1 was analyzed in the tissue TMA, which had been previously stained for Ecadherin expression. ZEB1 expression in stromal or endothelial cells was observed at 120 metastatic sites; however, only 10 metastases from nine individuals revealed nuclear ZEB1 expression in cancer cells (Figure 6E; see also Supplemental Figure S1 at http://ajp.amjpathol.org). Except for one individual with two ZEB1-positive metastases, all other individuals expressed only ZEB1 protein in one of several metastatic sites. Expression of ZEB1 was not specific to bone, lymph node, or soft tissue metastasis. Except for one ZEB1-positive case, which could not be evaluated because of loss of E-cadherin tissue cores, cancer cells that expressed ZEB1 also ex- pressed E-cadherin. Thus, both R-DU145 tumors in mice tumors and metastatic prostate cancers in patients coexpress ZEB1 and E-cadherin.

To determine whether a difference in SFK activity might account for the increased E-cadherin expression in tibial xenografts, SFK activity was tested in R-DU145 cells re-

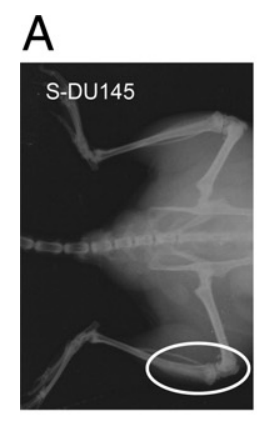

$0 / 5$

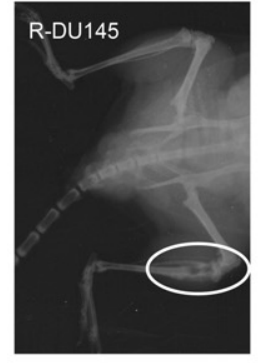

$8 / 10$

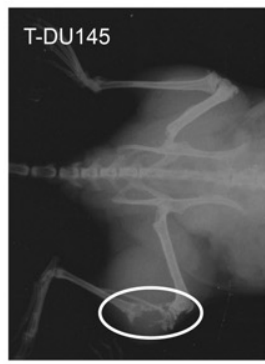

$5 / 5$
B

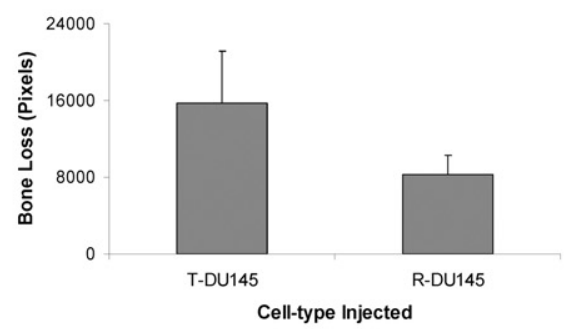

C

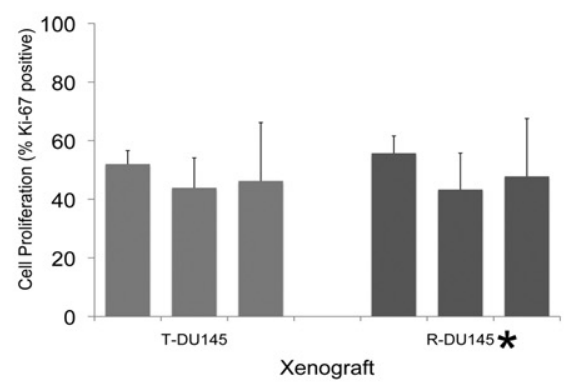

D

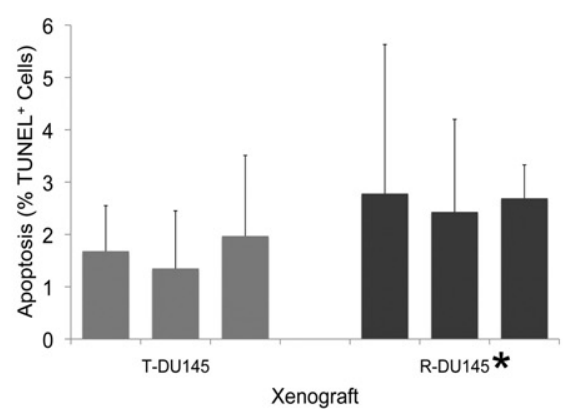

Figure 5. Growth of DU145 sublines in mouse tibia. A: Radiographs of tibial tumors from S-DU145, R-DU145, and T-DU145 cells. Tumor growth was followed up at radiography. Numbers indicate animals with tumors per total animals injected. Ovals demonstrate areas of osteolysis. B: Quantification of bone destruction in T-DU145 and R-DU145 xenografts. Bone destruction was measured by the loss of pixels in radiographs of four mice. C: Cell proliferation. Proliferation rates were measured using Ki-67 IHC. The percentage of Ki-67-positive tumor cells from three separate xenografts is shown. The difference in proliferation index is insignificant ( $\left.{ }^{*} P=0.74\right)$. D: Apoptosis. Apoptotic cells were visualized via TUNEL staining. The mean percentage per $40 \times$ high-powered field from three separate T-DU145 or R-DU145 xenografts is shown. The difference in the apoptotic index between T-DU145 and R-DU145 is significant $\left({ }^{*} P=0.03\right)$. 
A

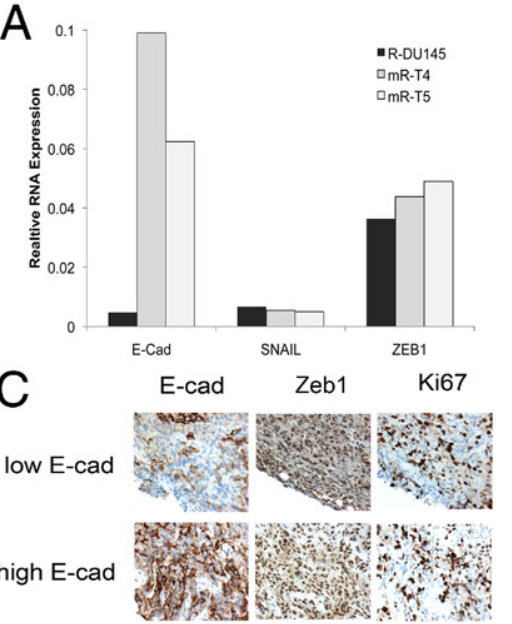

B

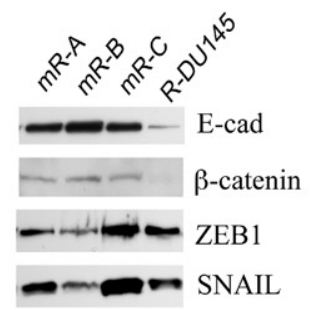

E

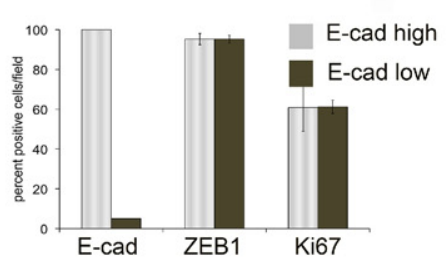

\begin{tabular}{|c|c|c|c|}
\hline Patient ID & Metastasis site & ZEB1 & E-cadherin \\
\hline $00-010$ & Lymph node & $1+$ & 2 \\
\hline $00-010$ & Liver & 0 & 2 \\
\hline $00-140$ & Lymph node & $1+$ & 1 \\
\hline $00-169$ & Lymph node & $1+$ & 2 \\
\hline $00-169$ & Bone & 0 & 2 \\
\hline $02-142$ & Soft other & $2+$ & 2 \\
\hline $02-142$ & Bone 1 & 0 & 2 \\
\hline $02-142$ & Bone 2 & 0 & 2 \\
\hline $98-323$ & Bone 1 & $1+$ & 2 \\
\hline $98-323$ & Bone 2 & 0 & 1 \\
\hline $98-323$ & Bone 3 & 0 & 1 \\
\hline $98-388$ & Bone 1 & $2+$ & 2 \\
\hline $98-388$ & Bone 2 & $2+$ & 2 \\
\hline $98-388$ & Liver & 0 & 2 \\
\hline $99-064$ & Bone & $2+$ & 1 \\
\hline 99-064 & Lymph node & 0 & 2 \\
\hline $99-069$ & Bone 1 & $2+$ & N/A \\
\hline 99-069 & Bone 2 & 0 & 2 \\
\hline 99-069 & Bone 3 & 0 & 1 \\
\hline 99-069 & Lymph node & 0 & 1 \\
\hline $99-090$ & Lymph node & $1+$ & 2 \\
\hline $99-090$ & Liver & 0 & 2 \\
\hline $99-090$ & Bone 1 & 0 & 2 \\
\hline $99-090$ & Bone 2 & 0 & 2 \\
\hline
\end{tabular}

Figure 6. Co-expression of E-cadherin and ZEB1 in xenografts and patient metastases. A: RNA expression in preinjection R-DU145 and two tibial xenografts, mR-T4 and m-RT5. RNA for E-cadherin, ZEB1, and SNAIL was measured using human-specific primers. B: Expression of protein in preinjection R-DU145 and in cells cultured from three tibial xenografts. R-DU145 cells from three tibiae (mR-A, mR-B, and mR-C) were briefly cultured ex vivo. Cells were analyzed for E-cadherin, $\beta$-catenin, ZEB1, and SNAIL using Western blot analysis. C: E-cadherin and ZEB1 are co-expressed in R-DU145 xenografts. Top left panels, Parallel sections of tibial xenografts were stained with E-cadherin (E-cad), ZEB1, and Ki-67. Bottom left panels, The percentage of ZEB1- or Ki-67-positive cells was quantified by counting E-cadherin-positive and E-cadherin-negative areas. D: SFK activity in R-DU145 cells. Cultured R-DU145 cells before and after injection were analyzed for pSFK. The Western blot membrane was reprobed for total expression of SFK, vimentin, and $\beta$-actin. VCAP cells were used as a positive control for SKF. E: E-cadherin and ZEB1 are co-expressed in patient tumor metastases. The TMA used in Figure 1 was stained with the ZEB1 antibody (S1), and cores were scored for ZEB1 expression in the nucleus of cancer cells. Cores positive for ZEB1 expression are shown in blue. E-cadherin expression in the same core is indicated in the column adjacent to ZEB1. ZEB1-negative metastatic sites are shown in yellow.

trieved from tibiae. SFK phosphorylation was lower in tibial cells than in preinjection R-DU145 cells (Figure 6D), which suggests that loss of SFK activity could have a role in increased E-cadherin expression.

Tibial xenografts were composed of both E-cadherinpositive and E-cadherin-negative regions. To exclude the possibility that E-cadherin expression in R-DU145 xenografts was caused by expansion of a small preexisting population of E-cadherin-positive cells, Ki-67 expression was measured in adjacent E-cadherin-positive and E-cadherin-negative areas (Figure 6C), and the same proliferation rates were observed. Thus, E-cadherin-positive cells do not demonstrate a growth advantage, and it was hypothesized that E-cadherin-positive cells in R-DU145 intratibial tumors are generated by conversion from E-cadherin-negative cells.

\section{Discussion}

Metastatic prostate cancers are extremely heterogeneous insofar as expression of the androgen receptor and cell proliferation. ${ }^{34}$ Therefore, the observed heterogeneity of E-cadherin expression is not unexpected. However, the significant difference between bone and soft tissue metastases was not anticipated and might explain the reason for differences in published studies, which include different ratios of bone and lymph node metastases. Another possibility for discrepant results is the method of decalcification of bone biopsy specimens. Strong E-cadherin expression was observed after decalcification with EDTA, whereas low E-cadherin expression was observed in bones decalcified with $7 \%$ nitric acid. ${ }^{28}$ It is likely that lower E-cadherin protein expression in lymph node and liver metastases, the two major sites of soft tissue metastases, is stimulated by factors in the microenvironment of tumor cells. However, the higher E-cadherin levels in bone are unexpected because bone contains high concentrations of transforming growth factor- $\beta$, hepatocyte growth factor, and Wnt ligands, which normally decrease E-cadherin expression.

Because of the complicated regulation of E-cadherin expression, an attempt was made to study cell populations that consist of cells with homogeneous expression levels of E-cadherin. This led to isolation of isogenic sublines from DU145 cells based on E-cadherin expression and provided three novel cell culture models with informative properties for investigation of the regulation of E-cadherin expression. In a previous study of DU145 sublines resembling S-DU145 and T-DU145 cells, the mechanism of E-cadherin regulation was not investigated. ${ }^{40}$ In that study, DU145 cells were fractionated on the basis of speed of migration, and the resulting $\mathrm{E}$ - 
cadherin-positive and E-cadherin-negative sublines differed in morphologic features, ultrastructure, and invasive capabilities. Our approach simply separated cells from the parent DU145 cell line on the basis of E-cadherin surface expression rather than functional features of cell migration or metastasis. ${ }^{41,42}$ Because E-cadherin surface-positive and surface-negative cell populations naturally coexist in the DU145 cell line, it is uncertain whether they were generated via EMT or exit from EMT. However, the data demonstrating that R-DU145 cells are capable of re-expressing E-cadherin in xenografts, as well as two studies that demonstrated increased E-cadherin expression in co-culture with hepatocytes ${ }^{43,44}$ support the possibility that in the right environment, DU145 cells can undergo exit from EMT.

Normally, cells that express E-cadherin are considered indolent, and EMT is associated with aggressive tumor behavior. Consistent with this theory, cells after EMT are more invasive and metastatic, and in several cancer types, high-grade tumors can assume a mesenchymal structure. Therefore, the aggressive growth behavior of E-cadherin-positive T-DU145 cells in mice was unexpected and suggests that E-cadherin-expressing cells might be more aggressive in metastatic tumors than in primary tumors. The link between E-cadherin expression and aggressive metastatic tumor growth was also made with TSU-Pr1 bladder carcinoma cells. ${ }^{45}$ Similar to observations in the present study, compared with mesenchymal sublines of TSU-Pr1, epithelioid TSU-Pr1 cells, stabilized by expression of FGFR2IIIc, demonstrated increased colonization of bone and soft tissues after cardiac or tibial injection.

The DU145 model provides additional mechanistic insights to previous studies in which epithelial plasticity was observed in prostate cancer. Both transcriptional and posttranslational regulatory mechanisms were identified involving ZEB1 and SFKs that are capable of regulating E-cadherin expression and also exert a broad affect on cellular structure, phenotype, and behavior. The multifaceted effects of ZEB1 and SFK in cancer cells suggest that E-cadherin expression might serve as a surrogate marker in tissues for several functional end points related to ZEB1 transcription and SFK phosphorylation. ${ }^{46,47}$ The most surprising observation in the DU145 model was the difference in the consequence of ZEB1 expression in cultured R-DU145 cells compared with R-DU145 cells in xenografts. Whereas ZEB1 is clearly capable of E-cadherin repression in cell culture, not only in R-DU145 cells but also in PC-3 and ARCaP cells, ${ }^{8,7} \mathrm{E}$-cadherin suppression by ZEB1 was lost in xenograft cells. It is unclear why ZEB1 cannot repress Ecadherin transcription in these cells. It is possible that posttranslational phosphorylation of ZEB1, which is required for ZEB1 activity, is not properly executed. ${ }^{48} \mathrm{Al}-$ ternatively, the silencing effects of ZEB1 may be overwhelmed by transcription factors that positively regulate E-cadherin transcription.

E-cadherin is critical for aggregation of embryonic stem cells ${ }^{49}$ and is induced in the generation of pluripotent stem cells from fibroblasts by OCT4, SOX2, KLF4, and c-MYC. ${ }^{50}$ Therefore, expression of stem cell genes in the sublines was evaluated. Among the three sublines, R-DU145 cells demonstrate the highest expression of genes associated with stem cells including HMGA2, ZFP42, KLF2, NESTIN, and SLAIN. ${ }^{51-54}$ R-DU145 cells also expressed s-SHIP mRNA, which is expressed in activated stem cells in developing mouse mammary tissue $^{55}$ (data not shown). Because R-DU145 cells in mouse xenografts express high ZEB1 and E-cadherin levels, and ZEB1 stimulates expression of microRNA found in stem cells, ZEB1 could maintain a stem cell phenotype in metastatic E-cadherin-positive prostate cancer cells. ${ }^{56}$ Therefore, R-DU145 cells might be a useful model to clarify the role of stem cell features during metastatic progression. ${ }^{57}$

The stem cell phenotype in EMT has been suggested as the responsible mechanism for drug resistance, and exit from EMT may change the response of cancer cells to drug therapy. The observation that R-DU145 cells from xenografts express reduced levels of active SFKs could have important therapeutic implications. Reduced SFK activity in metastasis in patients could cause resistance to Src inhibitors. An Src signature was recently observed in primary breast cancers to be associated with metastasis to bone, and in breast cancer cell lines, Src facilitated cell survival. ${ }^{58}$ Thus, as a conclusion from that study, it may be possible to kill dormant cells by inhibiting Src. However, our results caution coming to this conclusion because inhibition of Src might promote E-cadherin expression, which is associated with escape from dormancy and tumor growth. Thus, Src may have a different role in early and late metastatic prostate cancer cells, and as a consequence, Src inhibition may have different effects in early metastatic cancer cells from primary tumors compared with cancer cells from secondary or more advanced metastasis.

Morphologic features of EMT are not observed in Ecadherin-negative cells in primary or metastatic prostate cancers in patients and have led to the concept of "partial EMT." ${ }^{59}$ Consequently, the recovery from EMT, that is, exit from EMT, ${ }^{57}$ during metastatic progression, which has been postulated on the basis of high levels of Ecadherin expression in metastatic disease, requires further confirmation in prostate cancer. Other cancer types have been studied more extensively insofar as mechanisms of EMT. For example, disseminated breast cancer cells exhibit mesenchymal characteristics such as expression of TWIST and N-cadherin. ${ }^{60}$ Thus, more data from patients with prostate cancer are needed to enable understanding of the genetic reprogramming during prostate cancer metastasis.

In summary, results from three stable isogenic cell lines derived from the DU145 metastatic prostate cancer cell line support the concepts that $\mathrm{E}$-cadherin expression in metastatic prostate cancer is associated with aggressive disease; the environment of the bone marrow and bone in patients promotes E-cadherin expression; and ZEB1 and E-cadherin expression can be uncoupled in metastatic prostate cancer. Further studies of E-cadherin in metastatic prostate cancers in patients are needed to determine how E-cadherin expression is regulated and to 
determine the connection between E-cadherin expression, stem cell features, and treatment response.

\section{Acknowledgments}

We thank the patients who participated in the Prostate Cancer Donor Program and their families; Drs. Larry True, Celestia Higano, Martine Roudier, Paul Lange, Pete Nelson, and Bruce Montgomery and the rapid autopsy teams; and Shu Chen and Dr. Ruth Etzioni for statistical analysis. B.K. thanks Dr. George Vande Woude for stimulating and helpful discussions on epithelial plasticity.

\section{References}

1. Huber MA, Kraut N, Beug H: Molecular requirements for epithelialmesenchymal transition during tumor progression. Curr Opin Cell Biol 2005, 17:548-558

2. Zeisberg M, Kalluri R: The role of epithelial-to-mesenchymal transition in renal fibrosis. J Mol Med 2004, 82:175-181

3. Halbleib JM, Nelson WJ: Cadherins in development: cell adhesion, sorting, and tissue morphogenesis. Genes Dev 2006, 20:3199-3214

4. Cavallaro U, Christofori G: Multitasking in tumor progression: signaling functions of cell adhesion molecules. Ann NY Acad Sci 2004, 1014:58-66

5. Peinado H, Olmeda D, Cano A: Snail, Zeb and bHLH factors in tumour progression: an alliance against the epithelial phenotype? Nat Rev Cancer 2007, 7:415-428

6. Acloque H, Adams MS, Fishwick K, Bronner-Fraser M, Nieto MA: Epithelial-mesenchymal transitions: the importance of changing cell state in development and disease. J Clin Invest 2009, 119:1438-1449

7. Drake JM, Strohbehn G, Bair TB, Moreland JG, Henry MD: ZEB1 enhances transendothelial migration and represses the epithelial phenotype of prostate cancer cells. Mol Biol Cell 2009, 20:2207-2217

8. Graham TR, Zhau HE, Odero-Marah VA, Osunkoya AO, Kimbro KS, Tighiouart M, Liu T, Simons JW, O'Regan RM: Insulin-like growth factor-I-dependent up-regulation of ZEB1 drives epithelial-to-mesenchymal transition in human prostate cancer cells. Cancer Res 2008 68:2479-2488

9. Harris TJ, Tepass U: Adherens junctions: from molecules to morphogenesis. Nat Rev Mol Cell Biol 2010, 11:502-514

10. Giehl K, Menke A: Microenvironmental regulation of E-cadherinmediated adherens junctions. Front Biosci 2008, 13:3975-3985

11. Reynolds $A B$, Carnahan RH: Regulation of cadherin stability and turnover by p120ctn: implications in disease and cancer. Semin Cell Dev Biol 2004, 15:657-663

12. Kachhap SK, Faith D, Qian DZ, Shabbeer S, Galloway NL, Pili R, Denmeade SR, DeMarzo AM, Carducci MA: The N-Myc down regulated gene1 (NDRG1) is a Rab4a effector involved in vesicular recycling of E-cadherin. PLoS ONE 2007, 2:e844

13. Kong D, Banerjee S, Ahmad A, Li Y, Wang Z, Sethi S, Sarkar FH: Epithelial to mesenchymal transition is mechanistically linked with stem cell signatures in prostate cancer cells. PLoS One 2010, 5:e12445

14. Giannoni E, Bianchini F, Masieri L, Serni S, Torre E, Calorini L, Chiarugi P: Reciprocal activation of prostate cancer cells and cancerassociated fibroblasts stimulates epithelial-mesenchymal transition and cancer stemness. Cancer Res 2010, 70:6945-6956

15. Mak P, Leav I, Pursell B, Bae D, Yang X, Taglienti CA, Gouvin LM, Sharma VM, Mercurio AM: ERbeta impedes prostate cancer EMT by destabilizing HIF-1alpha and inhibiting VEGF-mediated SNAIL nuclear localization: implications for Gleason grading. Cancer Cell 2010, 17:319-332

16. Xie D, Gore C, Liu J, Pong RC, Mason R, Hao G, Long M, Kabbani W, Yu L, Zhang H, Chen H, Sun X, Boothman DA, Min W, Hsieh JT: Role of DAB2IP in modulating epithelial-to-mesenchymal transition and prostate cancer metastasis. Proc Natl Acad Sci USA 2010, 107:24852490
17. Cheng L, Nagabhushan M, Pretlow TP, Amini SB, Pretlow TG: Expression of E-cadherin in primary and metastatic prostate cancer. Am J Pathol 1996, 148:1375-1380

18. Umbas R, Isaacs WB, Bringuier PP, Xue Y, Debruyne FM, Schalken JA: Relation between aberrant alpha-catenin expression and loss of E-cadherin function in prostate cancer. Int J Cancer 1997, 74:374377

19. Kuczyk M, Serth J, Machtens S, Bokemeyer C, Bathke W, Stief C, Jonas U: Expression of E-cadherin in primary prostate cancer: correlation with clinical features. Br J Urol 1998, 81:406-412

20. De Marzo AM, Knudsen B, Chan-Tack K, Epstein JI: E-cadherin expression as a marker of tumor aggressiveness in routinely processed radical prostatectomy specimens. Urology 1999, 53:707-713

21. Kallakury BV, Sheehan CE, Ross JS: Co-downregulation of cell adhesion proteins alpha- and beta-catenins, p120CTN, E-cadherin, and CD44 in prostatic adenocarcinomas. Hum Pathol 2001, 32:849-855

22. Lu Q, Dobbs LJ, Gregory CW, Lanford GW, Revelo MP, Shappell S, Chen YH: Increased expression of delta-catenin/neural plakophilinrelated armadillo protein is associated with the down-regulation and redistribution of E-cadherin and p120ctn in human prostate cancer. Hum Pathol 2005, 36:1037-1048

23. Rao DS, Gui D, Koski ME, Popoviciu LM, Wang H, Reiter RE, Said JW: An inverse relation between COX-2 and E-cadherin expression correlates with aggressive histologic features in prostate cancer. Appl Immunohistochem Mol Morphol 2006, 14:375-383

24. Yuen HF, Chua CW, Chan YP, Wong YC, Wang X, Chan KW: Significance of TWIST and E-cadherin expression in the metastatic progression of prostatic cancer. Histopathology 2007, 50:648-658

25. van Oort IM, Tomita K, van Bokhoven A, Bussemakers MJ, Kiemeney LA, Karthaus HF, Witjes JA, Schalken JA: The prognostic value of E-cadherin and the cadherin-associated molecules alpha-, betagamma-catenin and p120ctn in prostate cancer specific survival: a long-term follow-up study. Prostate 2007, 67:1432-1438

26. Gravdal K, Halvorsen OJ, Haukaas SA, Akslen LA: A switch from $\mathrm{E}$-cadherin to $\mathrm{N}$-cadherin expression indicates epithelial to mesenchymal transition and is of strong and independent importance for the progress of prostate cancer. Clin Cancer Res 2007, 13:7003-7011

27. Umbas R, Schalken JA, Aalders TW, Carter BS, Karthaus HF, Schaafsma HE, Debruyne FM, Isaacs WB: Expression of the cellular adhesion molecule E-cadherin is reduced or absent in high-grade prostate cancer. Cancer Res 1992, 52:5104-5109

28. Pontes J Jr, Srougi M, Borra PM, Dall' Oglio MF, Ribeiro-Filho LA, Leite KR: E-cadherin and beta-catenin loss of expression related to bone metastasis in prostate cancer. Appl Immunohistochem Mol Morphol 2010, 18:179-184

29. Rubin MA, Mucci NR, Figurski J, Fecko A, Pienta KJ, Day ML: Ecadherin expression in prostate cancer: a broad survey using highdensity tissue microarray technology. Hum Pathol 2001, 32:690-697

30. Saha B, Arase A, Imam SS, Tsao-Wei D, Naritoku WY, Groshen S, Jones LW, Imam SA: Overexpression of E-cadherin and beta-catenin proteins in metastatic prostate cancer cells in bone. Prostate 2008 , 68:78-84

31. Darling DS, Stearman RP, Qi Y, Qiu MS, Feller JP: Expression of Zfhep/deltaEF1 protein in palate, neural progenitors, and differentiated neurons. Gene Expr Patterns 2003, 3:709-717

32. Shaw KR, Wrobel CN, Brugge JS: Use of three-dimensional basement membrane cultures to model oncogene-induced changes in mammary epithelial morphogenesis. J Mammary Gland Biol Neoplasia 2004, 9:297-310

33. Gmyrek GA, Walburg M, Webb CP, Yu H-M, You X, Vaughan ED, Vande Woude GF, Knudsen BS: Normal and malignant prostate epithelial cells differ in their response to hepatocyte growth factor/ scatter factor. Am J Pathol 2001, 159:579-590

34. Roudier MP, True LD, Higano CS, Vesselle H, Ellis W, Lange P, Vessella RL: Phenotypic heterogeneity of end-stage prostate carcinoma metastatic to bone. Hum Pathol 2003, 34:646-653

35. Liu AY, Corey E, Bladou F, Lange PH, Vessella RL: Prostatic cell lineage markers: emergence of BCL2+ cells of human prostate cancer xenograft LuCaP 23 following castration. Int J Cancer 1996, 65:85-89

36. Corey E, Quinn JE, Bladou F, Brown LG, Roudier MP, Brown JM, Buhler KR, Vessella RL: Establishment and characterization of osseous prostate cancer models: intra-tibial injection of human prostate cancer cells. Prostate 2002, 52:20-33 
37. Berx G, van Roy F: Involvement of members of the cadherin superfamily in cancer. Cold Spring Harb Perspect Biol 2009, 1:a003129

38. Sharma A, Yeow WS, Ertel A, Coleman I, Clegg N, Thangavel C, Morrissey C, Zhang X, Comstock CE, Witkiewicz AK, Gomella L, Knudsen ES, Nelson PS, Knudsen KE: The retinoblastoma tumor suppressor controls androgen signaling and human prostate cancer progression. J Clin Invest 2010, 120:4478-4492

39. Tsukamoto T, Nigam SK: Cell-cell dissociation upon epithelial cell scattering requires a step mediated by the proteosome. J Biol Chem 1999, 274:24579-24584

40. Chunthapong J, Seftor EA, Khalkhali-Ellis Z, Seftor RE, Amir S, Lubaroff DM, Heidger PM Jr, Hendrix MJ: Dual roles of E-cadherin in prostate cancer invasion. J Cell Biochem 2004, 91:649-661

41. Gao CF, Xie Q, Su YL, Koeman J, Khoo SK, Gustafson M, Knudsen BS, Hay R, Shinomiya N, Vande Woude GF: Proliferation and invasion: plasticity in tumor cells. Proc Natl Acad Sci USA 2005, 102:10528-10533

42. Bos PD, Zhang XH, Nadal C, Shu W, Gomis RR, Nguyen DX, Minn AJ, van de Vijver MJ, Gerald WL, Foekens JA, Massague J: Genes that mediate breast cancer metastasis to the brain. Nature 2009, 459: 1005-1009

43. Yates CC, Shepard CR, Stolz DB, Wells A: Co-culturing human prostate carcinoma cells with hepatocytes leads to increased expression of E-cadherin. Br J Cancer 2007, 96:1246-1252

44. Chao YL, Shepard CR, Wells A: Breast carcinoma cells re-express E-cadherin during mesenchymal to epithelial reverting transition. Mol Cancer 2010, 9:179

45. Chaffer CL, Brennan JP, Slavin JL, Blick T, Thompson EW, Williams ED: Mesenchymal-to-epithelial transition facilitates bladder cancer metastasis: role of fibroblast growth factor receptor-2. Cancer Res 2006, 66:11271-11278

46. Browne G, Sayan AE, Tulchinsky E: ZEB proteins link cell motility with cell cycle control and cell survival in cancer. Cell Cycle 2010, 9:886-891

47. Guarino M: Src signaling in cancer invasion. J Cell Physiol 2010, 223:14-26

48. Costantino ME, Stearman RP, Smith GE, Darling DS: Cell-specific phosphorylation of Zfhep transcription factor. Biochem Biophys Res Commun 2002, 296:368-373
49. Larue L, Antos C, Butz S, Huber O, Delmas V, Dominis M, Kemler R: A role for cadherins in tissue formation. Development 1996, 122 : 3185-3194

50. Wang Y, Mah N, Prigione A, Wolfrum K, Andrade-Navarro MA, Adjaye $\mathrm{J}$ : A transcriptional roadmap to the induction of pluripotency in somatic cells. Stem Cell Rev 2010, 6:282-296

51. Pfannkuche K, Summer H, Li O, Hescheler J, Droge P: The high mobility group protein HMGA2: a co-regulator of chromatin structure and pluripotency in stem cells?. Stem Cell Rev 2009, 5:224-230

52. Glover $\mathrm{CH}$, Marin M, Eaves CJ, Helgason CD, Piret JM, Bryan J: Meta-analysis of differentiating mouse embryonic stem cell gene expression kinetics reveals early change of a small gene set. PLoS Comput Biol 2006, 2:e158

53. Hoffman RM: The pluripotency of hair follicle stem cells. Cell Cycle 2006, 5:232-233

54. Hirst CE, Ng ES, Azzola L, Voss AK, Thomas T, Stanley EG, Elefanty AG: Transcriptional profiling of mouse and human ES cells identifies SLAIN1, a novel stem cell gene. Dev Biol 2006, 293:90-103

55. Bai L, Rohrschneider LR: S-SHIP promoter expression marks activated stem cells in developing mouse mammary tissue. Genes Dev 2010, 24:1882-1892

56. Wellner U, Schubert J, Burk UC, Schmalhofer O, Zhu F, Sonntag A, Waldvogel B, Vannier C, Darling D, zur Hausen A, Brunton VG, Morton J, Sansom O, Schuler J, Stemmler MP, Herzberger C, Hopt U, Keck T, Brabletz S, Brabletz T: The EMT-activator ZEB1 promotes tumorigenicity by repressing stemness-inhibiting microRNAs. Nat Cell Biol 2009, 11:1487-1495

57. van der Pluijm G: Epithelial plasticity, cancer stem cells and bone metastasis formation. Bone 2010, 48:37-43

58. Zhang XH, Wang Q, Gerald W, Hudis CA, Norton L, Smid M, Foekens $\mathrm{JA}$, Massague J: Latent bone metastasis in breast cancer tied to Src-dependent survival signals. Cancer Cell 2009, 16:67-78

59. Singh A, Settleman J: EMT, cancer stem cells and drug resistance: an emerging axis of evil in the war on cancer. Oncogene 2010, 29:47414751

60. Schmidt-Kittler O, Ragg T, Daskalakis A, Granzow M, Ahr A, Blankenstein TJ, Kaufmann M, Diebold J, Arnholdt H, Muller P, Bischoff J, Harich D, Schlimok G, Riethmuller G, Eils R, Klein CA: From latent disseminated cells to overt metastasis: genetic analysis of systemic breast cancer progression. Proc Natl Acad Sci USA 2003, 100:77377742 